\title{
Czech Historical Atlas: A web map portal on the Czech history
}

\author{
Jiří Krejčí ${ }^{\mathrm{a},}$, Petra Jílková ${ }^{\mathrm{b}}$ * \\ ${ }^{a}$ Czech Technical University in Prague, Faculty of Civil Engineering, Department of Geomatics, Czechia, jirikrejci@fsv.cvut.cz \\ ${ }^{b}$ Czech Technical University in Prague, Faculty of Civil Engineering, Department of Geomatics, Czechia, petra.jilkova@fsv.cvut.cz \\ * Corresponding author: petra.jilkova@fsv.cvut.cz
}

Keywords: historical atlas, web map portal, web application, historical cartography, Czech Historical Atlas

\begin{abstract}
:
The web map portal Czech Historical Atlas presents a digital output of a synthesis of two printed historical atlases published within the long-term cooperation of a team of cartographers from the Department of Geomatics, CTU in Prague and a team of historians from the Institute of History of the Academy of Sciences of the Czech Republic. The topics and chapters from these two atlases were carefully selected and combined to effectively present historical topics dealing mainly with the geographical area of the Czech lands. The map content is depicted via the most modern cartographic methods employing the advanced functionality of the web environment.
\end{abstract}

The structure of the map portal has been designed considering user friendliness with an emphasis on simple and intuitive control. Therefore, it is easily accessible to the general public of all ages. The content of the portal is divided into eight chapters - Borders and Territories, Borders and Regions, the Czech State and Europe in the 20th Century, Populations, Religion and Faith, Historical Milestones, Periods and Consequences, War Conflicts and Their Consequences, and Landscape and Humans. Each of the chapters is then further divided into several subchapters which represent separate web map applications presenting a set of temporally or thematically related maps (see Fig. 1).
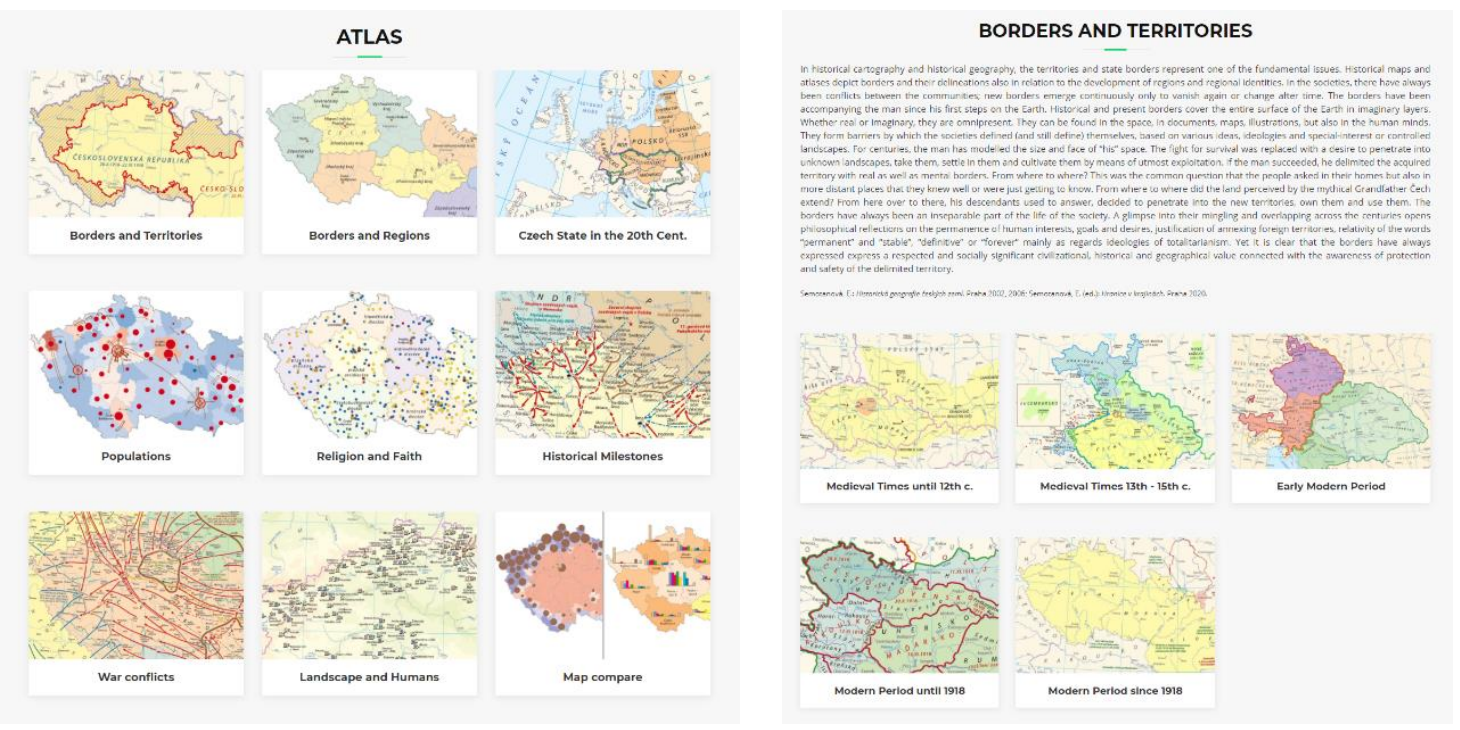

Figure 1. Thematic structure of the web map portal - main chapters (left) and subchapters (right).

Map applications are supplemented by accompanying texts with a list of basic literature, which briefly describes the certain thematic subchapter or the particular maps. Moreover, a number of illustrations from public and private collections is provided. These illustrations (e.g. old maps, historical and present photographs) significantly supplement the thematic content of the map and enrich the perception of historical processes illustrated through the cartographic representation.

The map portal is not just a common web site referring to individual map applications or topics. It is complemented by a number of texts on the issues of historical cartography as a scientific field and it refers to other works of historical cartography, both printed and digital. The web map portal, as well as individual map applications, is based on ESRI platform using standard web technologies HTML, CSS, JavaScript and PHP.

The map portal is available in Czech and English versions at www.czechhistoricalatlas.cz. 


\section{Acknowledgements}

This work was supported by the Grant Agency of the Czech Technical University in Prague, grant No. SGS21/054/OHK1/1T/11. 